\title{
From near-surface to root-zone soil moisture using an exponential filter: an assessment of the method based on in-situ observations and model simulations
}

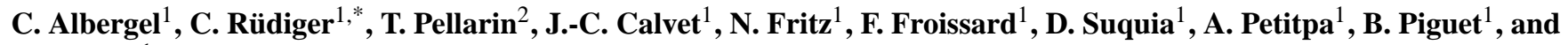 \\ E. Martin ${ }^{1}$ \\ ${ }^{1}$ CNRM/GAME (Météo-France, CNRS), Toulouse, France \\ ${ }^{2}$ LTHE (UMR 5564), Grenoble, France \\ *now with: Department of Civil and Environmental Engineering, The University of Melbourne, Melbourne, Australia
}

Received: 16 May 2008 - Published in Hydrol. Earth Syst. Sci. Discuss.: 24 June 2008

Revised: 4 November 2008 - Accepted: 4 November 2008 - Published: 10 December 2008

\begin{abstract}
A long term data acquisition effort of profile soil moisture is under way in southwestern France at 13 automated weather stations. This ground network was developed in order to validate remote sensing and model soil moisture estimates. In this paper, both those in situ observations and a synthetic data set covering continental France are used to test a simple method to retrieve root zone soil moisture from a time series of surface soil moisture information. A recursive exponential filter equation using a time constant, $T$, is used to compute a soil water index. The Nash and Sutcliff coefficient is used as a criterion to optimise the $T$ parameter for each ground station and for each model pixel of the synthetic data set. In general, the soil water indices derived from the surface soil moisture observations and simulations agree well with the reference root-zone soil moisture. Overall, the results show the potential of the exponential filter equation and of its recursive formulation to derive a soil water index from surface soil moisture estimates. This paper further investigates the correlation of the time scale parameter $T$ with soil properties and climate conditions. While no significant relationship could be determined between $T$ and the main soil properties (clay and sand fractions, bulk density and organic matter content), the modelled spatial variability and the observed inter-annual variability of $T$ suggest that a weak climate effect may exist.
\end{abstract}

Correspondence to: J.-C. Calvet (calvet@meteo.fr)

\section{Introduction}

Microwave remote sensing provides a means to quantitatively describe the water content of a shallow near-surface soil layer, $w_{g}$ (Schmugge, 1983). However, the variable of interest for applications in short- and medium-range meteorological modelling and hydrological studies over vegetated areas is the root-zone soil moisture content $\left(w_{2}\right)$, which controls plant transpiration. Since the near-surface soil moisture is related to the root-zone soil moisture through diffusion processes, assimilation algorithms may allow the retrieval of $w_{2}$ from observed $w_{g}$ (Entekhabi et al., 1994; Houser et al., 1998; Calvet and Noilhan, 2000; Walker et al., 2001a, b). Estimation of profile soil moisture from intermittent remotely sensed soil moisture data has focused on the assimilation of such data into land surface models (Ragab, 1995; Walker, 2001a; Sabater et al., 2007). Land surface models with a thin topsoil layer, consistent with the nature of the remotely sensed observations are required in such an approach. Several authors concluded that the Kalman Filter, an optimal sequential assimilation method extensively used in various environmental problems, is well suited for profile soil moisture estimation (Walker et al., 2001b). Other assimilation techniques such as 1DVAR also provide good results under controlled conditions (Sabater et al., 2007). However, the lack of high quality information on the model parameters at a global scale (soil properties, atmospheric forcing) and the uncertainties related to the physical description of the water and energy balance are a disadvantage for data assimilation methods. In a land surface model, the conversion from surface to root-zone soil moisture may depend on multiple

Published by Copernicus Publications on behalf of the European Geosciences Union. 
factors such as soil texture or vegetation coverage (Calvet and Noilhan, 2000) and the analysed profile soil moisture is model-dependent. The chosen assimilation method may also affect the results (Sabater et al., 2007).

Wagner et al. (1999) proposed to use an exponential filter to estimate the soil water index (SWI) of the root-zone from remotely sensed surface soil moisture time series. A single parameter $(T)$ has to be determined, which implicitly takes many physical parameters into account. The rationale for retrieving a SWI, instead of root-zone soil moisture values is that over a large footprint, the variability of soil characteristics may be very high and may not be represented accurately. In this context, only the relative dynamic range of the soil water content can be represented (Rüdiger et al., 2008). Data assimilation methods are based on unbiased observations. In the case of soil moisture, this is tantamount to using SWI values. A number of studies have already shown the potential of this method using data from the scatterometer on board the European Remote Sensing Satellite (Wagner, 1999; Ceballos et al., 2005; Pellarin et al., 2006). Consequently, this approach may be tested using other existing or future remotely sensed data sets.

The SMOS satellite (Soil Moisture and Ocean Salinity, ESA/CNES), scheduled for launch in 2009, consists of a spaceborne L-band interferometric radiometer able to provide global estimates of surface soil moisture with a sampling time step of 2-3 days at the equator and a ground resolution of $50 \mathrm{~km}$ (Kerr et al., 2001). It is the first satellite designed with the intention to measure soil moisture over land. Ground-truth measurements of soil moisture at various locations and covering large climatic gradients (several hundreds of $\mathrm{km}$ ) will permit to validate the SMOS surface soil moisture products and to analyse $w_{2}$, once the SMOS data are available at a global scale.

This will be achieved by making use of several soil moisture observation networks, such as the SMOSMANIA (Soil Moisture Observing System-Meteorological Automatic Network Integrated Application) network in southwestern France (Calvet et al., 2007). With SMOSMANIA, soil moisture profile measurements at 12 locations of the automatic weather station network of Météo-France, the RADOME (Réseau d'Acquisition de Données d'Observations Météorologiques Etendu) network, have been obtained since early 2007 . This group of stations forms a $400 \mathrm{~km}$ transect along the climatic gradient between the Atlantic Ocean and the Mediterranean Sea, with all stations being equipped with probes measuring the volumetric soil moisture content at various depths. SMOSMANIA is a long-term data acquisition effort of profile soil moisture observations that will be used to support the validation of soil moisture estimates derived from SMOS observations. Other remote sensing products from AMSR-E (Advanced Microwave Scanning Radiometer for Earth Observing System), WindSAT (a satellite based polarimetric microwave radiometer), or
ASCAT (Advanced Scatterometer on METOP) may be validated by SMOSMANIA as well, together with model soil moisture estimates over France (Rüdiger et al., 2008).

The SMOSREX (Surface Monitoring Of the Soil Reservoir EXperiment) experimental site (De Rosnay et al., 2006) is located along the same transect and is also included in the validation effort, as SMOSREX includes profile soil moisture measurements.

In this paper, the SMOSMANIA project and its scientific objectives are first presented. This is followed by a definition of an exponential filter (Wagner et al., 1999) which allows to estimate the SWI from intermittent surface soil moisture measurements, as well as its recursive formulation (Stroud, 1999). The exponential filter equation, which is the operational filtering method for ERS and ASCAT data, uses a single tuning parameter: a time constant, $T$. In this study, the recursive formulation is used and the filter is applied to the surface soil moisture measurements obtained with SMOSMANIA and SMOSREX to estimate the root-zone soil moisture at a depth of $30 \mathrm{~cm}$. In order to explore the link between $T$ and the local environmental characteristics (such as soil properties, depth, etc.), a similar study is performed with synthetic data from the SAFRAN-ISBA-MODCOU (SIM; SAFRAN atmospheric forcing data base; ISBA land surface model; MODCOU hydrological routing model) model suite applied over continental France (Habets et al., 2008).

\section{Material and methods}

\subsection{Definition of soil moisture variables}

Different soil moisture variables are used in this study:

- $w_{g}$ is the water content $\left(\mathrm{m}^{3} \mathrm{~m}^{-3}\right)$ of a surface soil layer, $5 \mathrm{~cm}$ for SMOSMANIA stations, $0-6 \mathrm{~cm}$ for SMOSREX, a few mm for SIM.

- $w_{2}$ is the root-zone soil moisture content $\left(\mathrm{m}^{3} \mathrm{~m}^{-3}\right)$, measured at $30 \mathrm{~cm}$ (SMOSMANIA), at various depths (SMOSREX), or integrated over the root-zone profile (SIM and SMOSREX).

- Prior to filtering, surface soil moisture $w_{g}$ observations or simulations are scaled between $[0,1]$ using maximum and minimum values of each time series (ms, dimensionless).

- The dimensionless root-zone $\mathrm{SWI}_{\mathrm{obs}}$ used in Sect. 3.1, Eq. (7), to assess the quality of the results, is the reference $w_{2}$ (either observed in situ or simulated by SIM) scaled to $[0,1]$ using maximum and minimum values of each time series. $\mathrm{SWI}_{m}$ is the result of the exponential filter and of its recursive formulation. It is dimensionless and ranges from 0 to 1 . A scaled SWI allows to combine the different dynamic ranges of surface soil moisture and profile soil moisture. This is essential, as 
the surface may show soil moisture values below the wilting point and above field capacity, while the profile soil moisture is generally bound by those two parameters.

\subsection{SMOSMANIA}

The main objective of the SMOSMANIA network is to validate remote sensing soil moisture products. However, the use of observations obtained from SMOSMANIA is not limited to satellite validation and other objectives include: (i) the validation of the operational soil moisture products of MétéoFrance, produced by the hydrometeorological model SIM (Habets et al., 2005, 2008), (ii) the validation of new versions of the land surface model of Météo-France (ISBA), and (iii) ground-truthing of future airborne $\mathrm{Cal} / \mathrm{Val}$ campaigns in support of the SMOS mission. For the first time, automatic measurements of soil moisture have been integrated in an operational meteorological network which results in a unique data set.

The SMOSMANIA network is based on the existing automatic weather station network of Météo-France (RADOME). The RADOME stations observe air temperature and relative humidity, wind speed and precipitation. At some stations the downwelling shortwave radiation is also measured. Twelve existing stations of RADOME in southwestern France were chosen. They are listed in Table 1, from East to West. The stations form a Mediterranean-Atlantic transect (Fig. 1) following the marked climatic gradient between the two coastlines. The locations of the chosen stations are in relatively flat areas (mountainous areas are avoided as much as possible) and the altitude of the highest station (MTM) is $538 \mathrm{~m}$ a.s.l. The three most eastward stations (NBN, LZC and MTM) are representative of a Mediterranean climate. The average distance between two neighbouring stations is approximately $45 \mathrm{~km}$ which is consistent with the spatial resolution of the future SMOS footprints. The vegetation cover at those sites consists of natural fallow, cut once or twice a year. Four soil moisture probes were horizontally installed per station at depths of 5,10,20 and $30 \mathrm{~cm}$. The ThetaProbe ML2X of Delta-T Devices was chosen because it has successfully been used during previous long-term campaigns of Météo-France and because it can easily be interfaced with the RADOME stations. The ThetaProbe is a capacitance probe using the dielectric permittivity properties of the soil to estimate the volumetric soil moisture content (White et al., 1994). The impedance of its array of four prongs varies with the two components of the soil impedance: the apparent dielectric constant and the ionic conductivity. As output, the ThetaProbe provides a voltage signal in unit of $\mathrm{V}$ (White et al., 1994) and its variation is virtually proportional to changes in the soil moisture content over a large dynamic range.
Table 1. Soil characteristics of the 12 stations of the SMOSMANIA network at four depths $(5,10,20$ and $30 \mathrm{~cm})$ : clay and sand fractions, organic matter, and bulk density. The stations are listed from East to West (Narbonne to Sabres).

\begin{tabular}{|c|c|c|c|c|c|}
\hline Stations & $\begin{array}{l}\text { Depth } \\
(\mathrm{cm})\end{array}$ & $\begin{array}{l}\text { Clay } \\
\left(\mathrm{g} \mathrm{kg}^{-1}\right)\end{array}$ & $\begin{array}{l}\text { Sand } \\
\left(\mathrm{g} \mathrm{kg}^{-1}\right)\end{array}$ & $\begin{array}{l}\text { Organic matter } \\
\left(\mathrm{g} \mathrm{kg}^{-1}\right)\end{array}$ & $\begin{array}{l}\text { Bulk density } \\
\left(\mathrm{kg} \mathrm{m}^{-3}\right)\end{array}$ \\
\hline \multicolumn{6}{|c|}{ Narbonne (NBN) } \\
\hline & 5 & 464 & 262 & 62.4 & 1260 \\
\hline & 10 & 492 & 232 & 54.6 & 1545 \\
\hline & 20 & 455 & 268 & 45.6 & 1237 \\
\hline & 30 & 428 & 315 & 44.6 & 1237 \\
\hline \multicolumn{6}{|c|}{ Lézignan Corbières (LZC) } \\
\hline & 5 & 273 & 440 & 29.6 & 1383 \\
\hline & 10 & 251 & 490 & 20.8 & 1498 \\
\hline & 20 & 262 & 497 & 18.3 & 1468 \\
\hline & 30 & 278 & 510 & 17.0 & 1468 \\
\hline \multicolumn{6}{|c|}{ Mouthoumet (MTM) } \\
\hline & 5 & 294 & 420 & 71.0 & 1438 \\
\hline & 10 & 305 & 411 & 61.8 & 1540 \\
\hline & 20 & 278 & 452 & 59.5 & 1561 \\
\hline & 30 & 298 & 419 & 47.5 & 1600 \\
\hline \multicolumn{6}{|c|}{ St Félix de Lauragais (SFL) } \\
\hline & 5 & 228 & 435 & 19.6 & 1575 \\
\hline & 10 & 224 & 403 & 14.2 & 1533 \\
\hline & 20 & 239 & 397 & 16.5 & 1524 \\
\hline & 30 & 294 & 320 & 11.9 & 1553 \\
\hline \multicolumn{6}{|c|}{ Montaut (MNT) } \\
\hline & 5 & 150 & 283 & 33.2 & 1405 \\
\hline & 10 & 153 & 313 & 19.4 & 1444 \\
\hline & 20 & 146 & 299 & 14.2 & 1562 \\
\hline & 30 & 154 & 276 & 10.8 & 1458 \\
\hline \multicolumn{6}{|c|}{ Savenes (SVN) } \\
\hline & 5 & 194 & 361 & 12.8 & 1425 \\
\hline & 10 & 193 & 339 & 11.6 & 1453 \\
\hline & 20 & 195 & 346 & 10.7 & 1532 \\
\hline & 30 & 353 & 239 & 5.6 & 1532 \\
\hline \multicolumn{6}{|c|}{ Lahas (LHS) } \\
\hline & 5 & 353 & 278 & 27.2 & 1518 \\
\hline & 10 & 410 & 207 & 25.8 & 1500 \\
\hline & 20 & 404 & 223 & 25.3 & 1535 \\
\hline & 30 & 395 & 217 & 19.2 & 1370 \\
\hline \multicolumn{6}{|c|}{ Condom (CDM) } \\
\hline & 5 & 410 & 148 & 17.2 & 1419 \\
\hline & 10 & 442 & 134 & 25.5 & 1522 \\
\hline & 20 & 456 & 124 & 20.5 & 1460 \\
\hline & 30 & 460 & 133 & 19.2 & 1574 \\
\hline \multicolumn{6}{|c|}{ Peyrusse Grande (PRG) } \\
\hline & 5 & 417 & 158 & 39.8 & 1285 \\
\hline & 10 & 423 & 156 & 31.3 & 1476 \\
\hline & 20 & 440 & 175 & 18.1 & 1449 \\
\hline & 30 & 501 & 121 & 15.1 & 1536 \\
\hline \multicolumn{6}{|c|}{ Créon d'Armagnac (CRD) } \\
\hline & 5 & 57 & 881 & 44.5 & 1305 \\
\hline & 10 & 53 & 884 & 27.1 & 1435 \\
\hline & 20 & 47 & 898 & 28.3 & 1615 \\
\hline & 30 & 50 & 878 & 23.2 & 1412 \\
\hline \multicolumn{6}{|c|}{ Urgons (URG) } \\
\hline & 5 & 157 & 159 & 27.6 & 1370 \\
\hline & 10 & 158 & 154 & 21.9 & 1500 \\
\hline & 20 & 152 & 164 & 19.8 & 1530 \\
\hline & 30 & 172 & 144 & 8.1 & 1590 \\
\hline \multicolumn{6}{|c|}{ Sabres (SBR) } \\
\hline & 5 & 39 & 932 & 18.8 & 1460 \\
\hline & 10 & 42 & 937 & 16.5 & 1680 \\
\hline & 20 & 36 & 934 & 18.3 & 1678 \\
\hline & 30 & 38 & 946 & 19.2 & 1645 \\
\hline
\end{tabular}




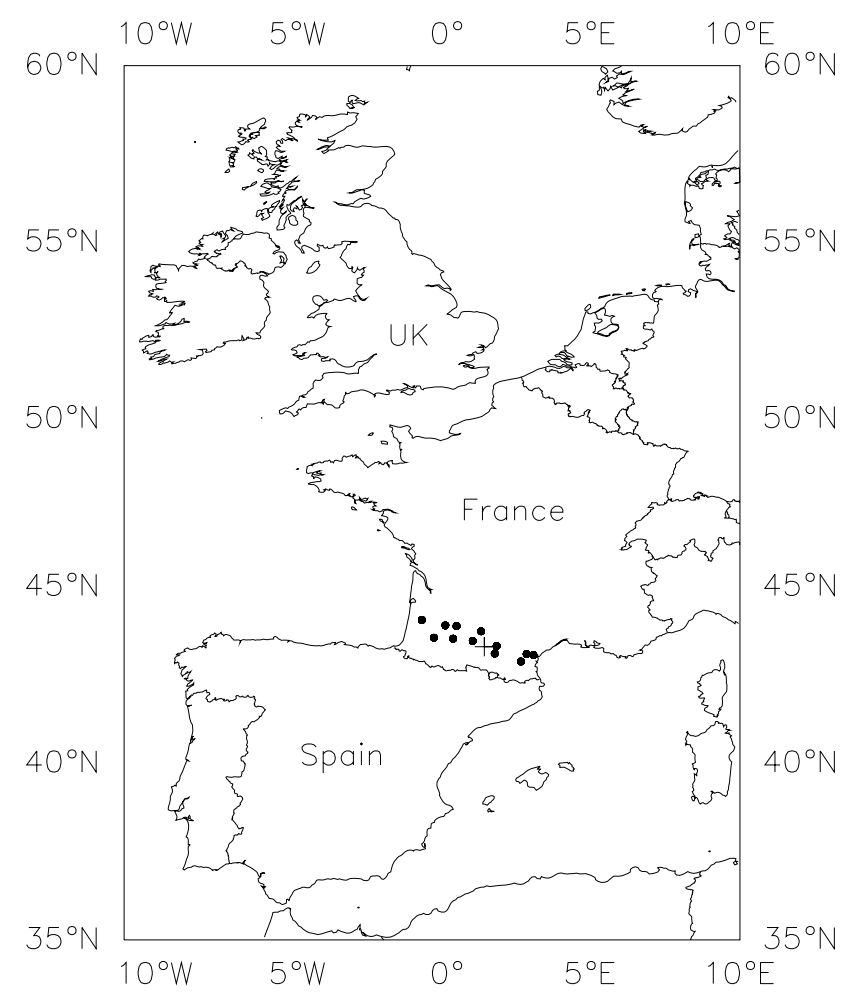

Fig. 1. Map illustrating the SMOSMANIA network located in southwestern France (full dots) forming a $400 \mathrm{~km}$ transect between the Atlantic ocean and the Mediterranean sea. The "+" symbol is for the SMOSREX station. The stations are equipped with sensors measuring volumetric soil moisture content and soil temperature at various depths.

Site-specific calibration curves were developed using insitu gravimetric soil samples in order to convert the voltage signal into volumetric soil moisture content $\left(\mathrm{m}^{3} \mathrm{~m}^{-3}\right)$. As calibrations have to be performed for each soil type (i.e. for all stations) and for each depth, 48 calibrations curves were obtained for the SMOSMANIA network. The calibration was performed both in-situ (through regular gravimetric sampling around the station performed in 2006 and 2007) and in a laboratory set-up (monitoring of a given sample in various controlled conditions). Exponential calibration curves were found to represent best the relationship between the volumetric soil moisture content and the voltage measured by the sensor. The ThetaProbes are set to perform measurements at regular intervals of $12 \mathrm{~min}$. They were installed in 2006 and have been operational since then, so that data covering the whole 2007 annual cycle and the two first months of 2008 are available for this study.

Figures 2 and 3 show the $5 \mathrm{~cm}\left(w_{g}\right)$ and $30 \mathrm{~cm}$ $\left(w_{2}\right)$ volumetric soil moisture content $\left(\mathrm{m}^{3} \mathrm{~m}^{-3}\right)$ for the 12 SMOSMANIA stations, respectively, over a period of 14 months (January 2007-February 2008) and at $12 \mathrm{~min}$ time intervals. Except for the stations of LHS, MTM and LZC, there is a good agreement between surface soil moisture and deepest soil moisture. The squared correlation coefficient $\left(r^{2}\right)$ between $w_{g}$ and $w_{2}$ is greater than 0.5 .

During the installation of the soil moisture probes, soil samples where collected for each of the four depths of the soil moisture profile $(5,10,20$ and $30 \mathrm{~cm})$. Those samples were used to determine soil texture, soil organic matter and bulk density (see Table 1).

\subsection{SMOSREX}

Located at the ONERA (Office National d'Etudes et de Recherches Aérospatiales) site of Fauga-Mauzac, near Toulouse in southwestern France (Fig. 1), the SMOSREX experiment (De Rosnay et al., 2006) aims at improving the modelling of the microwave L-band emission of the soilvegetation system as well as improving the understanding of soil-plant-atmosphere interactions. The SMOSREX site consists of two plots (one of bare soil, one with fallow), observed by an L-band radiometer (LEWIS) installed at the top of a central structure, $15 \mathrm{~m}$ a.g.l. Operations began in January 2001 with the monitoring of soil moisture and temperature profiles. Soil moisture measurements are taken by ThetaProbes at depths of $0-6 \mathrm{~cm}, 10,20,30,40,50,60,70$, 80 and $90 \mathrm{~cm}$ and are available from January 2001 to December 2007 with an half-hourly time step. Using the soil moisture observations at each depth the integrated soil moisture in the root-zone is defined as the arithmetic average of those observations.

\subsection{SIM}

In the present study, the SIM model suite SAFRAN-ISBAMODCOU is used to compute a surface $w_{g}$ and a root-zone $w_{2}$ soil moisture data base over continental France from 1 August 2002 to 31 August 2004.

SAFRAN (Système d'analyse fournissant des renseignements atmosphériques à la neige) (Durand et al., 1993) is a mesoscale atmospheric analysis system for surface variables and was initially developed in order to provide an analysis of the atmospheric forcing in mountainous areas for snow depth and avalanche forecasting. The SAFRAN analysis provides the main atmospheric forcing parameters (precipitation, air temperature, air humidity, wind speed, incident radiation) using information from more than 1000 meteorological stations and more than 3500 daily rain gauges throughout France. An optimal interpolation method is used to assign values for each analysed variable. It was shown that a good correlation between the SAFRAN data base and in-situ observations exists (Quintana-Segui et al., 2008).

The land surface scheme in SIM is ISBA (Interaction between Soil, Biosphere and Atmosphere) in which the hydrology is based on the equations of the force-restore approach (Noilhan and Planton, 1989; Noilhan and Mahfouf, 1996). 

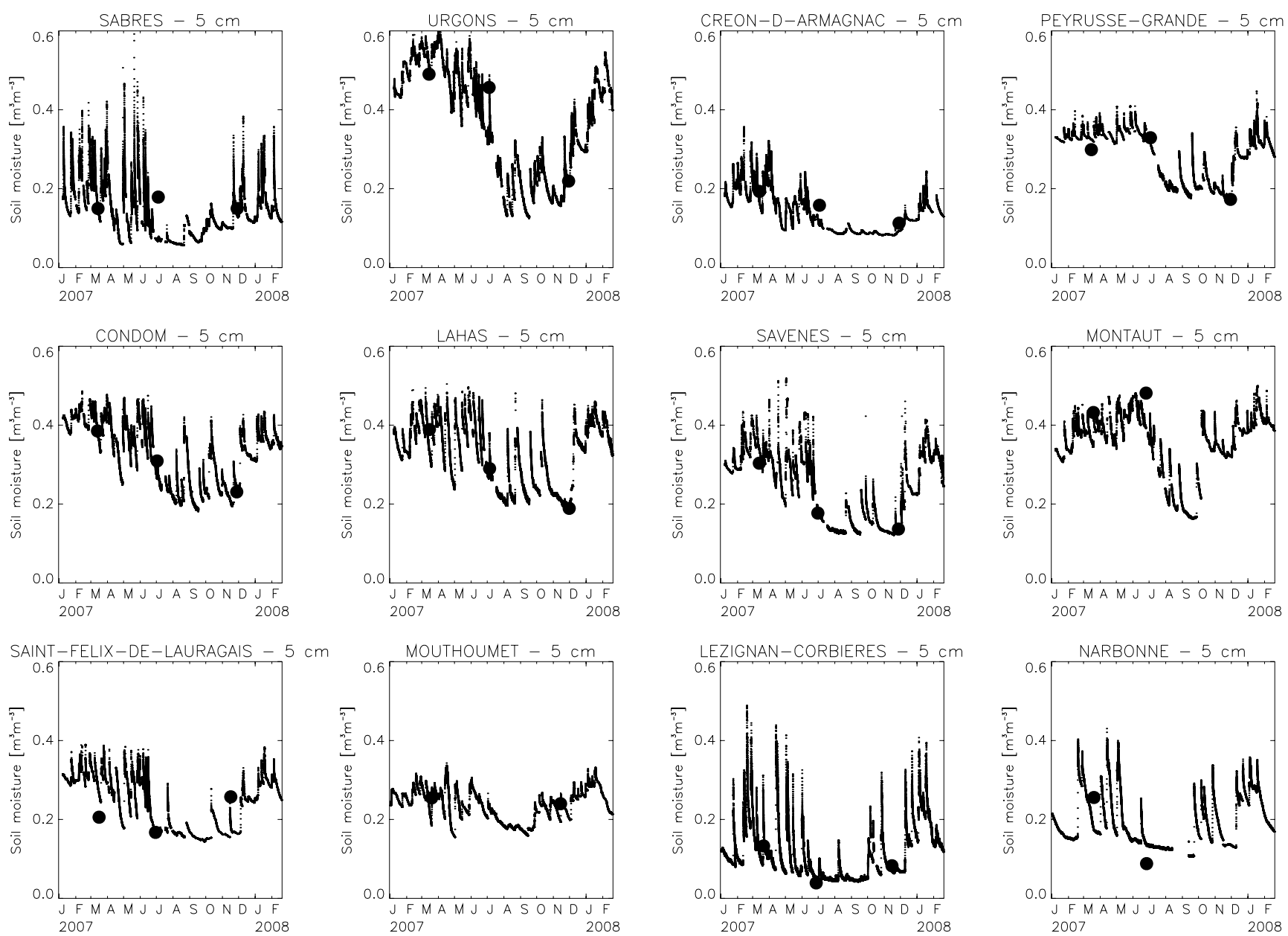

Fig. 2. Volumetric soil moisture measured for the 12 stations of the SMOSMANIA network over a 14 month period (from January 2007 to February 2008), at a depth of $5 \mathrm{~cm}$ : continuous observations with an automatic probe (solid line), and soil moisture obtained through gravimetric measurements (dots).

The soil layer and soil moisture dynamics are modelled within a 3-soil-layer model (Boone et al., 1999) with the soil and vegetation parameters being derived from a global data base of soils and ecosystems (ECOCLIMAP; Masson et al., 2003). For the purpose of the land surface simulations, the ISBA parameters, provided by ECOCLIMAP at a resolution of $1 \mathrm{~km}$, were aggregated to the model resolution of $8 \mathrm{~km}$. The ISBA model simulations were performed at this resolution.

MODCOU is a hydrogeological model and was not used in the current study.

SIM was extended to the whole of continental France in 2002 in order to monitor water resources at the national scale in near real-time (Habets et al., 2008). In total, SIM consists of a 9892 pixel data base. For each pixel, data such as surface and rootzone soil moisture, the thickness of the soil layer, fraction of clay and sand, LAI (Leaf Area Index), and the atmospheric forcing are available. For hydrological pur- poses, the database exceeds the political borders and covers, in particular, regions of Germany and Switzerland (over these regions, the quality of the atmospheric forcing is reduced as no ground observation is used in the analysis).

The $w_{g}$ data set is used to derive a spatially and temporally distributed $\mathrm{SWI}_{m}$ product, described in Sect. 3.4, which is based on the exponential filter. In Sect. 4, the retrieved $\mathrm{SWI}_{m}$ is compared to the reference $w_{2}$, scaled to $[0,1]$ using maximum and minimum values of the time series.

\subsection{The exponential filter}

Past studies have shown that the profile soil moisture content is often reasonably well correlated with the surface soil moisture. The problem is that no clear relationship between the regression coefficients and the characteristics of the site could be identified (Jackson, 1986). Recognising the need for a more physical approach, Jackson et al. (1980) suggested 

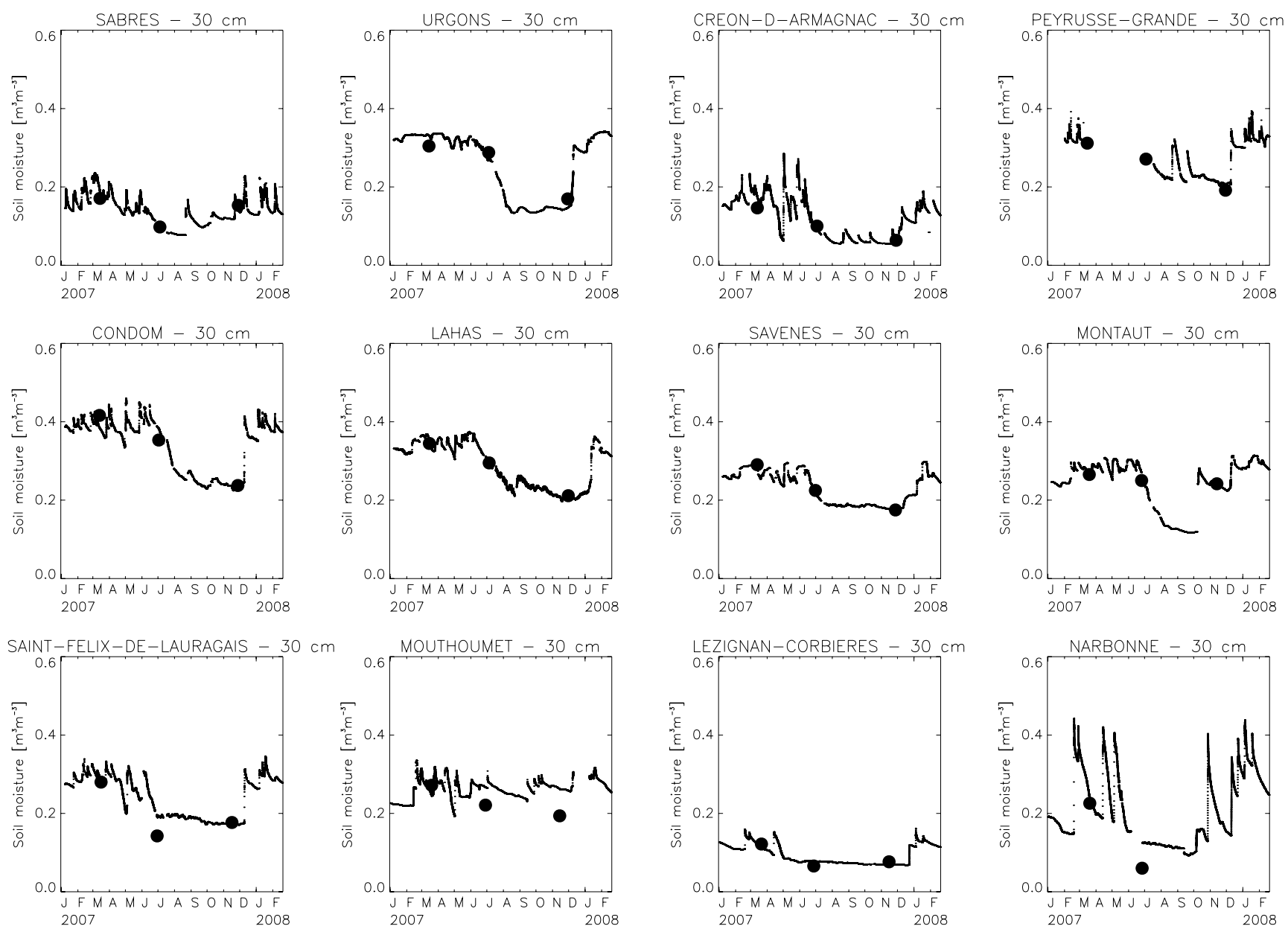

Fig. 3. Volumetric soil moisture measured for the 12 stations of the SMOSMANIA network over a 14 month period (from January 2007 to February 2008), at a depth of $30 \mathrm{~cm}$ : continuous observations with an automatic probe (solid line), and soil moisture obtained through gravimetric measurements (dots).

the use of a water movement simulation model to compute the vertical moisture distribution in the soil profile. Assuming that hydrologic equilibrium conditions are satisfied, and provided soil properties are known, it is possible to estimate the profile soil moisture content from instantaneous surface observations. However, this assumption of near-equilibrium does not occur after rainfall and is not likely to be valid at daytime due to the high variability of the energy and water budget. To avoid the decoupling between $w_{g}$ and $w_{2}$ after rainfall events, long time series may be correlated to the root-zone, and to avoid the daytime decoupling, surface soil moisture measurements should be taken during the morning (Jackson et al., 1980).

Several approaches can be used in order to relate profile soil moisture to surface soil moisture (Houser et al., 1998; Walker et al., 2001b; Sabater et al., 2007). In a simplified two-layer water-balance approach, the root-zone soil moisture can be estimated by convoluting the surface soil mois- ture time series with an exponential filter (Wagner et al., 1999). The top layer $w_{g}$ is regarded as the remotely sensed surface layer and the second layer $w_{2}$ as a "reservoir" below. Once assuming that the water flux between those two layers is proportional to the difference in soil moisture content between the two layers, a simple water balance equation Eq. (1) can be used to establish a connection between $w_{2}$ and $w_{g}$ :

$L \frac{d w_{2}(t)}{d t}=C \cdot\left[w_{g}(t)-w_{2}(t)\right]$

where $L$ is the depth of the second layer, $t$ represents time and $C$ is an area-representative pseudo-diffusivity constant. Under the assumption that $C$ is constant and $T=L / C$, the integration of Eq. (1) is:

$w_{2}(t)=\frac{1}{T} \int_{-\infty}^{t} w_{g}(\tau) \exp \left[-\frac{t-\tau}{T}\right] d \tau$

In this case, the parameter $T$ represents a characteristic time length. This parameter can be considered as a surrogate 
parameter for all the processes affecting the temporal dynamics of soil moisture, such as the thickness of the soil layer, soil hydraulic properties, evaporation, run-off and vertical gradient of soil properties (texture, density). $T$ represents the time scale of soil moisture variation, in units of day (Ceballos et al., 2005). Different important processes such as transpiration are not considered in Eq. (2). Additionally, it is assumed that the soil hydraulic conductivity is constant while it may vary in reality by several orders of magnitude depending on the soil moisture conditions (Wagner et al., 1999).

Remotely sensed data provide measurements at irregular time intervals, thus the continuous formulation of Eq. (2) is replaced by a discrete equation (Wagner et al.,1999):

$$
\operatorname{SWI}_{m}\left(t_{n}\right)=\frac{\sum_{i}^{n} \operatorname{ms}\left(t_{i}\right) e^{-\frac{t_{n}-t_{i}}{T}}}{\sum_{i}^{n} e^{-\frac{t_{n}-t_{i}}{T}}}
$$

where $\operatorname{ms}\left(t_{i}\right)$ is surface soil moisture, estimated from remote sensing at time $t_{i}$. The scaled and therefore dimensionless surface soil moisture content is retrieved in Wagner et al. (1999) by first extrapolating the observed backscatter to a reference angle of 40 degrees and then scaling this observation between the maximum and minimum values observed during the instrument's lifetime. This discontinuous time series replaces the continuous parameter $w_{g}(t)$. The quantity $w_{2}(t)$ is replaced by the Soil Water Index $\left(\mathrm{SWI}_{m}\right)$. The $\mathrm{SWI}_{m}$ at time $t_{n}$ is calculated if there is at least one measurement in the time interval $\left[t_{n}-T, t_{n}\right]$ and at least 4 measurements in the interval $\left[t_{n}-3 T, t_{n}\right]$ (Pellarin et al., 2006).

$\mathrm{SWI}_{m}$ is a trend indicator ranging from 0 to 1 . For estimating the water in deeper layer, auxiliary information like soil physical properties are required. In Wagner et al. (1999) a plant available water (PAW) content is derived from the $\mathrm{SWI}_{m}$ by using auxiliary information about the soil physical properties (wilting point, field capacity and total water capacity), and thus converting relative values into absolute soil moisture content. Equation (3) was validated against insitu measurements by Ceballos et al. (2005) in the semi-arid region of the Duero Basin in Spain. They found a statistically significant coefficient of determination $\left(r^{2}=0.75\right)$ and a RMSE of $0.022 \mathrm{~m}^{3} \mathrm{~m}^{-3}$ when comparing the PAW values derived from scatterometer and area-averaged field measurements $(0-100 \mathrm{~cm})$.

\subsection{Recursive formulation of the exponential filter}

In contrast to Wagner et al. (1999), Stroud (1999) presents a recursive formulation of the exponential filter. In the case of soil moisture, the following recursive equation can be written:

$\mathrm{SWI}_{m(n)}=\mathrm{SWI}_{m(n-1)}+K_{n}\left(\operatorname{ms}\left(t_{n}\right)-\mathrm{SWI}_{m(n-1)}\right)$ where the gain $K$ at time $t_{n}$ is given by:

$$
K_{n}=\frac{1}{1+\sum_{i}^{n-1} e^{-\frac{\left(t_{n}-t_{i}\right)}{T}}}
$$

This gain may also be written in a recursive form as:

$$
K_{n}=\frac{K_{n-1}}{K_{n-1}+e^{-\frac{\left(t_{n}-t_{n-1}\right)}{T}}}
$$

The range of the gain $K$ is $[0,1]$. In the presence of extensive temporal data gaps (relative to the filter time scale), Eq. (6) tends toward unity. In that particular case, the previous estimates are disregarded when new observations are obtained and the new estimate takes on the value of the new observation. For the initialisation of the filter, $K_{1}=1$ and $\mathrm{SWI}_{m(1)}=\mathrm{ms}\left(t_{1}\right)$.

This recursive formulation can handle data more easily than the original exponential filter (Eq. 3), as the only requirement for an update of the $\mathrm{SWI}_{m}$ is (apart from the previous $\mathrm{SWI}_{m}$ and $K$ values) the availability of a new $\operatorname{ms}\left(t_{n}\right)$ observation and the time interval since the last observation $\left(t_{n}-t_{n-1}\right)$.

In this study, the recursive formulation of the exponential filter, as proposed by Stroud (1999), was used. Both methods are mathematically equal. However, the initialisation and the implementation of the recursive and non-recursive filters differ (the recursive formulation suppresses the need to prescribe an integration interval and to store past time series). It was verified that the two methods yield similar results for the SMOSMANIA network and at the SMOSREX station.

\section{Application of the exponential filter}

In this study, only in-situ surface soil moisture observations taken at 06:00 Local Standard Time (LST) at the 12 SMOSMANIA stations and at SMOSREX are used. Similarly, only the 6 a.m. simulations were extracted from the SIM data base. The 6 a.m. time was chosen as this will be the morning/descending overpass time of SMOS. Moreover, even though measurements obtained with the ThetaProbe impedance soil moisture probes used in the SMOSREX and SMOSMANIA experiments are moderately sensitive to temperature, this effect may interfere with soil moisture measurements in dry conditions, when bound-water fraction is important (Escorihuela et al., 2007). As this effect may vary from one soil type to another, it cannot be accounted for easily. This undesired effect is more pronounced in the afternoon (more frequent dryer and warmer conditions at the top soil layer). The recursive filter Eqs. (4)-(6) were applied to the $w_{g}$ data scaled between $[0,1]$. 


\subsection{Statistical scores}

In order to assess the quality of the exponential filter, the correlation coefficient $(r)$, the root mean square error (RMSE), the bias and the Nash-Sutcliffe coefficient $(N)$ were determined. The Nash-Sutcliffe coefficient $N$ is defined as

$N=1-\frac{\sum_{i}\left(\mathrm{SWI}_{\mathrm{obs}}(i)-\mathrm{SWI}_{m}(i)\right)^{2}}{\sum_{i}\left(\mathrm{SWI}_{\mathrm{obs}}(i)-\mu \mathrm{SWI}_{\mathrm{obs}}\right)^{2}}$

where $\mathrm{SWI}_{m}(i)$ and $\mathrm{SWI}_{\mathrm{obs}}(i)$ are the modelled and observed SWI at time $i$. The $\mu \mathrm{SWI}_{\mathrm{obs}}$ value is the overall average of the observed (reference) SWI. $N$ can range from $-\infty$ to 1 . A value of 1 corresponds to a perfect match between modelled and observed data. A value of 0 indicates that the model predictions are as accurate as the mean of the observed data, whereas a value of less than 0 occurs if the observed mean is a better predictor than the model output (Nash and Sutcliffe, 1970).

\subsection{SMOSMANIA}

For each SMOSMANIA station, the $w_{g}$ soil moisture observations at a depth of $5 \mathrm{~cm}$, scaled between $[0,1]$ using the minimum and maximum values of each time series, are used to calculate $\mathrm{SWI}_{m}$. The calculated $\mathrm{SWI}_{m}$ is then compared to $w_{2}$ (soil moisture observations at $30 \mathrm{~cm}$, the deepest observation at the SMOSMANIA stations) scaled to $[0,1]$ using the minimum and maximum values of each time series, for different values of $T$ (up to 40 days). At SMOSREX, soil moisture observations are available from the surface down to $90 \mathrm{~cm}$, and a SWI ${ }_{\mathrm{obs}}$ representing the fully integrated scaled root-zone soil moisture can be computed. The analysis of SMOSREX data (not shown) indicates that local soil moisture observations at depths ranging from $20 \mathrm{~cm}$ to $50 \mathrm{~cm}$ are significantly correlated to the root-zone soil moisture integrated over the whole profile. The $r^{2}$ values over a period of three years (2001-2003) exceed 0.9. For the SMOSMANIA network, it is assumed that scaled soil moisture observations at $30 \mathrm{~cm}$ are a good proxy of the scaled root-zone soil moisture.

For each station the $T$ parameter corresponding to the best value of a statistical score $(N$ or $r)$ is determined and is called $T_{\text {opt }}$. In general the $N$ value was used to optimise $T$, except for the stations of MTM and SBR. While the highest $N$ value retrieved for the former is negative for any value of $T$, the retrievals of the latter always result in an underestimation of the root-zone soil moisture and is very low, 0.016. Consequently, the $T$ values at those stations were optimised using $r$ between the retrieved $\mathrm{SWI}_{m}$ and $w_{2}$.

\subsection{SMOSREX}

The values of $w_{g}$ (surface $(0-6 \mathrm{~cm})$ soil moisture observations) at SMOSREX are used to calculate $\mathrm{SWI}_{m}$ over a 7 year period (2001-2007) using the exponential filter for different values of $T$ (up to 40 days). The $\mathrm{SWI}_{m}$ values are compared to $w_{2}$ (the soil moisture observations at $30 \mathrm{~cm}$ and then at other depths from $10 \mathrm{~cm}$ down to $90 \mathrm{~cm}$ ) and to the soil moisture integrated over the root-zone.

\subsection{SIM}

Surface soil moisture information from the 9892 grid cells of the SIM database are used to compute $\mathrm{SWI}_{m}$. In SIM, $w_{g}$ corresponds to a skin soil moisture (a few $\mathrm{mm}$ at the soil surface), and $w_{2}$ corresponds to the total soil moisture content of the second soil layer of ISBA. The thickness of this layer may vary from one grid cell to another. For each grid cell, different $T$ values are used in order to retrieve $T_{\text {opt }}$ corresponding to the highest value of $N . T_{\mathrm{opt}}$ was optimised over the two year period of the data base (2003-2004). Negative values of $N$ are sometimes observed over mountainous and dense urban areas (not shown). Over mountainous areas, perturbing physical factors (snow, soil freezing) affect the sensitivity of $w_{g}$ to $w_{2}$. Over dense urban areas, the soil moisture simulated by SIM is not relevant. The grid cells for which the maximum $N$ is negative are excluded from the database. As a consequence, a 9258 grid cell database is available with $T_{\text {opt }}$, and the scores of the $\mathrm{SWI}_{m}$ retrieval $(r, \mathrm{RMSE}$, bias and $N$ ) versus the reference simulated $w_{2}$.

\section{Analysis of the results}

In this section, the $T_{\mathrm{opt}}$ values obtained with the methodology described in Sect. 3 are presented, along with the corresponding $r$, RMSE, bias and $N$, in Tables 2 and 3 for SMOSMANIA (the 12 stations) and SMOSREX, respectively. Figures 4 to 12 illustrate the results obtained with the in situ data of SMOSMANIA and SMOSREX, and with the synthetic data of SIM.

\subsection{Performance of the exponential filter}

The performance of the exponential filter for retrieving the scaled root-zone soil moisture from the available surface soil moisture information was examined for a 14 month period at the 12 SMOSMANIA stations, for 7 annual cycles of SMOSREX (2001-2007), and for 2 years (2003-2004) with the SIM simulations. 
SABRES
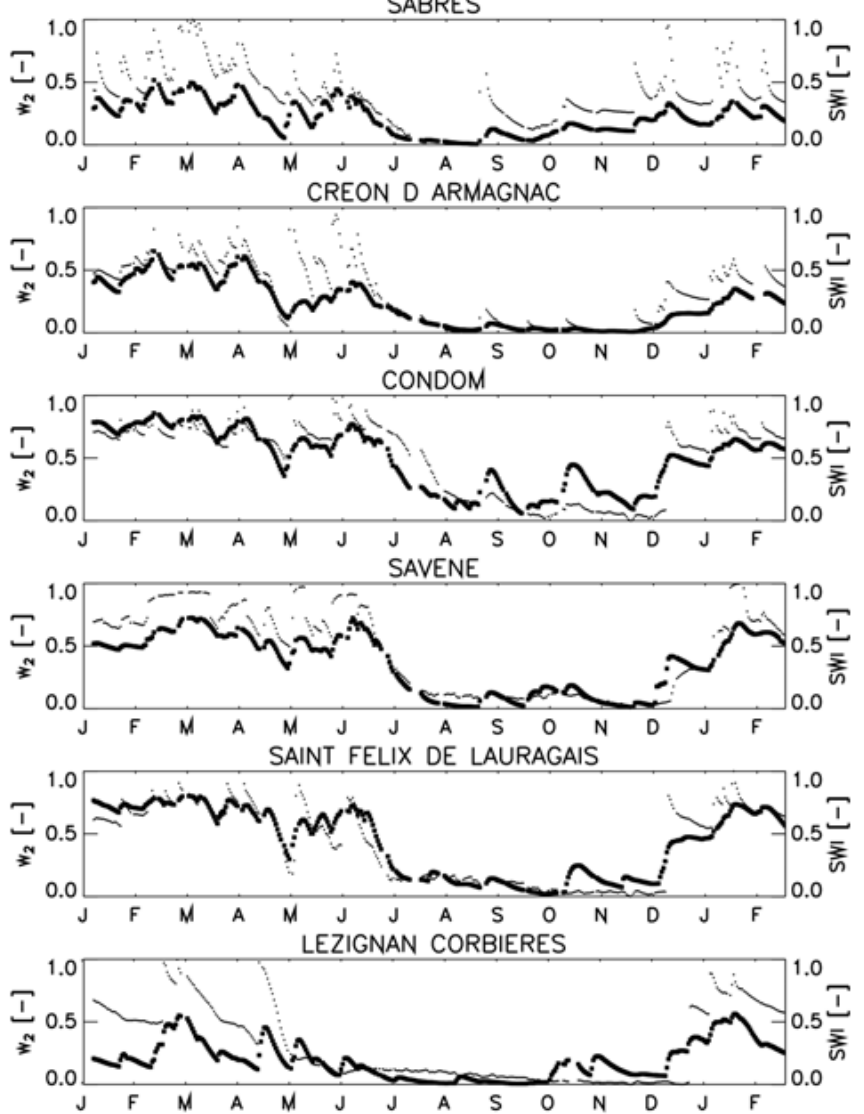
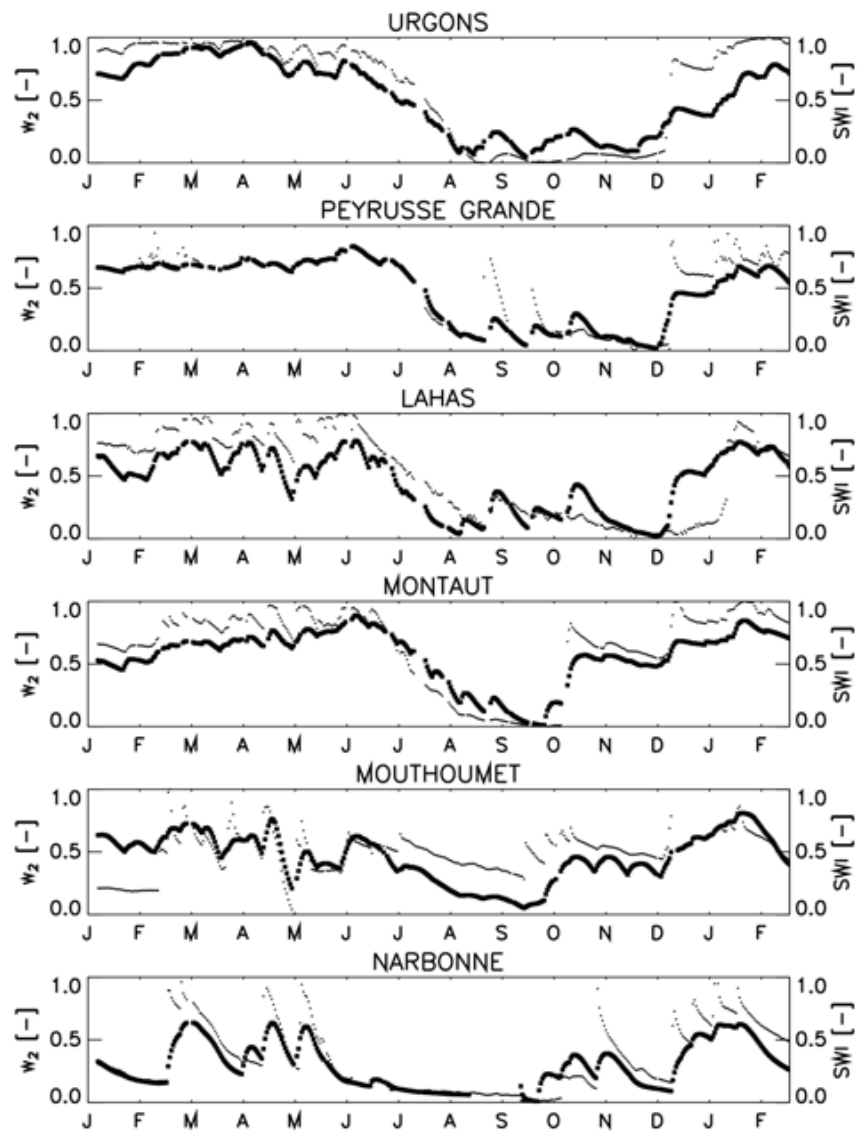

Fig. 4. Soil water index $\left(\mathrm{SWI}_{m}[-]\right)$ at $30 \mathrm{~cm}$ derived from $w_{g}[-]$ (scaled surface soil moisture observations at $5 \mathrm{~cm}$, large dots) and $w_{2}[-]$ (scaled soil moisture observations at $30 \mathrm{~cm}$, small dots), for the 12 stations of SMOSMANIA over a 14 month period. The characteristic time length of the exponential filter $T=6$ days is used, i.e. the mean value of the 12 optimised $T$ parameters.

\subsubsection{SMOSMANIA}

Table 2 shows good $\mathrm{SWI}_{m}$ retrieval results for the majority of the SMOSMANIA stations, at a depth of $30 \mathrm{~cm}: 7$ stations present $N$ values higher than 0.7 (SFL, MNT, SVN, LHS, CDM, PRG, URG). Fair values of $N$ are obtained for NBN and CRD (0.675 and 0.635, respectively). Results for LZC are poor $(N=0.376)$ and negative or very low values of $N$ are obtained for MTM and SBR (see Sect. 3.2). Despite the biased retrieval of MTM and SBR, seasonal dynamics in the root-zone soil moisture are well retrieved. It is interesting to note that most $N$ values lower than 0.7 are observed at the stations presenting the highest fraction of sand (Table 1): the average fraction of sand at LZC, MTM, CRD, SBR is higher than $40 \%$.

The values of $r$ and RMSE are less contrasting than $N$, from one station to another. The average $r$ and RMSE are 0.88 and 0.16 , respectively. The average bias is 0.076 .

The RMSE represents the relative error of the soil moisture dynamical range. With an average dynamic range of $0.194 \mathrm{~m}^{3} \mathrm{~m}^{-3}$ for the SMOSMANIA network at $30 \mathrm{~cm}$ depth, and an average RMSE value of 0.163 , an estimate of the average error of the root-zone soil moisture retrieval is about $0.031 \mathrm{~m}^{3} \mathrm{~m}^{-3}$.

The retrieved $T_{\mathrm{opt}}$ values presented in Table 2 range from 1 to 23 days, with an average of 6 days. In order to test the sensitivity of the exponential filter to changes in $T_{\text {opt }}$ (or to the use of a single $T_{\text {opt }}$ value for all the stations), $T$ was set to 6 days for all sites. The new value of $N$ for each site is also shown in Table 2. The $\mathrm{SWI}_{m}$ for all stations of the SMOSMANIA network, calculated with $T_{\text {opt }}$ set to 6 days, are presented on Fig. 4 along with the reference $w_{2}$. Although the initial $T_{\text {opt }}$ ranges from 1 to 23 days, peaks and troughs are still well represented with the averaged $T_{\text {opt }}=6$ days. The majority of the sites maintain a high value of $N$, which suggests that the sensitivity to changes in $T$ is limited.

The evolution of $N$ as a function of $T$ for the 12 SMOSMANIA stations is shown in Fig. 5. It is obvious that several monitoring sites have a large range of possible $T_{\mathrm{opt}}$ values with a high $N$. These results support the findings of Wagner (1998), who stated that the approach may be relatively insensitive to $T$. 


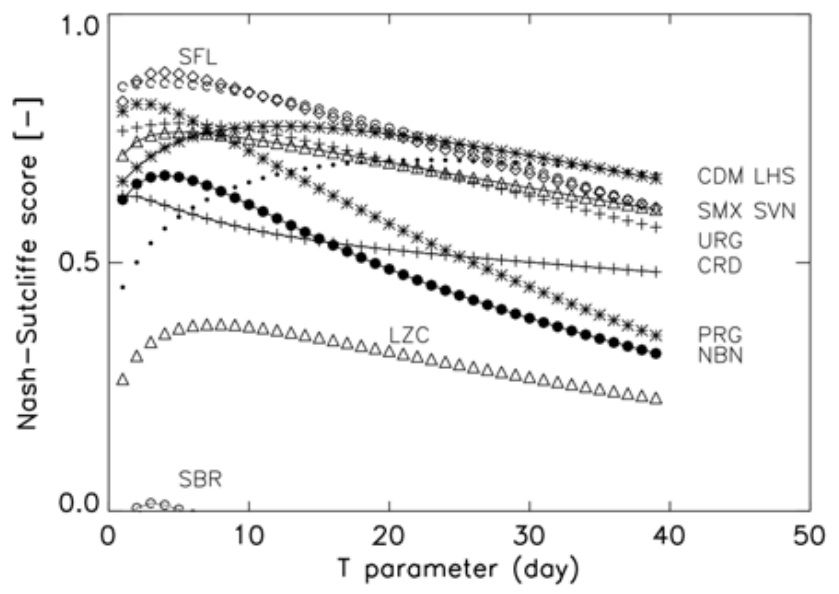

Fig. 5. Nash-Sutcliffe score of the $\mathrm{SWI}_{m}[-]$ at $30 \mathrm{~cm}$ derived from $w_{g}[-]$ (scaled surface soil moisture observations at $5 \mathrm{~cm}$ ) versus the characteristic time length $T$ used in the exponential filter for the 12 SMOSMANIA stations (Table 1) and for the SMOSREX station (SMX) from 2001 to 2007. SBR, open circles and full line, SMX, open circles, URG, +, CRD, + and full line, PRG, * $, \mathrm{CDM},{ }^{*}$ and full line, LHS, dots, SVN, triangles and full line, SFL, diamonds, LZC, triangles, NBN, solid circles and full line, MNT, diamonds and full line, $N$ values for MTM station are negative (see Table 2).

\subsubsection{SMOSREX}

As the SMOSREX time series of soil moisture covers 7 annual cycles, $T_{\mathrm{opt}}$ was determined for each individual year, to gain an understanding of the inter-annual variability of this parameter. Table 3 presents $T_{\mathrm{opt}}$ for each year and for the whole period $\left(T_{\mathrm{opt}}=6\right.$ days $)$, and the corresponding $w_{2}$ statistical scores. The value of $N$ ranges from 0.557 to 0.935 , with a mean of 0.845 . For $T_{\mathrm{opt}}=6$ days a $N$ value of 0.858 is obtained. The average $r$ and RMSE are 0.946 and 0.113 , respectively. The bias for the whole period is 0.026 . The difference between the $N$ values corresponding to the annual $T_{\mathrm{opt}}$ or to $T_{\mathrm{opt}}=6$ days is low, which is consistent with the results obtained with the data from the SMOSMANIA network (Sect. 4.1.1). The optimisation of the calculated $\mathrm{SWI}_{m}$ on the basis of the $\mathrm{SWI}_{\mathrm{obs}}$ obtained from the integrated soil moisture observations over the complete root-zone depth at SMOSREX yields a $T_{\text {opt }}$ of 11 days and an $N$ value of 0.837 , which is only marginally lower than the $N$ value for $30 \mathrm{~cm}$.

The retrieval of $\mathrm{SWI}_{m}$ at $30 \mathrm{~cm}$ for the SMOSREX site is shown on Fig. 6 for $T_{\mathrm{opt}}=6$ days along with the scaled observations at $30 \mathrm{~cm}$ for the period of January 2001 to December 2007 (minimum and maximum values over the 7 year period are used to scale the observations). The two time series compare generally well but two shortcomings are observed:

- In order to assess the impact of the interannual variability on the method, $w_{g}$ is scaled between $[0,1]$ using the minimum and maximum values of the whole 7 year period. At wintertime, while the observations
Table 2. The retrieved optimum characteristic time length $T_{\mathrm{opt}}$ of the recursive formulation of an exponential filter for each SMOSMANIA station, at $w_{2}$ (a depth of $30 \mathrm{~cm}$ ). Statistical scores are given for each station: the correlation coefficient $r$, the root mean square error (RMSE), the bias, the Nash-Sutcliffe coefficient $(N)$ corresponding to $T_{\mathrm{Opt}}$, and to the average $T_{\mathrm{opt}}$ (6 days).

\begin{tabular}{lrrrrll}
\hline Stations & $T_{\text {opt }}$ & $r$ & RMSE & bias & $N$ & $\begin{array}{l}N \text { for } \\
T_{\text {opt }}=6 \text { days }\end{array}$ \\
\hline NBN & 4 & 0.887 & 0.145 & 0.074 & 0.675 & 0.672 \\
LZC & 8 & 0.826 & 0.231 & 0.126 & 0.376 & 0.367 \\
MTM & 1 & 0.495 & 0.193 & 0.043 & negative & negative \\
SFL & 4 & 0.940 & 0.102 & -0.008 & 0.882 & 0.879 \\
MNT & 2 & 0.958 & 0.134 & 0.080 & 0.796 & 0.777 \\
SVN & 5 & 0.952 & 0.161 & 0.098 & 0.762 & 0.762 \\
LHS & 23 & 0.926 & 0.180 & 0.067 & 0.706 & 0.591 \\
CDM & 12 & 0.888 & 0.137 & 0.009 & 0.774 & 0.743 \\
PRG & 2 & 0.932 & 0.126 & 0.057 & 0.818 & 0.798 \\
CRD & 1 & 0.912 & 0.151 & 0.105 & 0.635 & 0.605 \\
URG & 5 & 0.931 & 0.183 & 0.086 & 0.780 & 0.780 \\
SBR & 4 & 0.895 & 0.217 & 0.184 & 0.016 & negative \\
\hline
\end{tabular}

reach saturation, a saturation of the retrieved $\mathrm{SWI}_{m}$ is not achieved every year. However this condition is obtained if $w_{g}$ is scaled separately on a year by year basis.

- At summertime, the retrieved $\mathrm{SWI}_{m}$ overestimates the observations during the relatively wet years of 2001 and 2002. These periods display strong, but short precipitation events that resulted in a wet surface and consequently a high estimated $\mathrm{SWI}_{m}$, whereas the in situ soil moisture profile observations show that those precipitation were not strong enough to increase $w_{2}$.

A possible seasonal impact on the $T$ parameter for the 7 year period of SMOSREX was investigated. Instead of applying the filter with $T=6$ days to the whole period, the filter was applied season by season (winter, spring, summer, autumn, with $T$ values optimised for each season pooled over the 7 year period, of 2, 3, 4 and 6 days, respectively). The seasonal $\mathrm{SWI}_{m}$ values were then aggregated and compared to the scaled observations at $30 \mathrm{~cm}$. The obtained $N$ value (0.717) is lower than for the standard method (0.858).

\subsubsection{SIM}

The spatial variability of $T_{\mathrm{opt}}$ over continental France was analysed thanks to the SIM database. Figure 7 shows maps of $N$ and $T_{\text {opt }}$ over the SIM domain for all the grid cells (i.e. for spatially varying values of thickness of the root-zone and soil texture). Median values of $N$ and $T_{\mathrm{opt}}$ are 0.68 and 15 days, respectively.

An example of retrieval is given in Fig. 8 for one grid cell $\left(4.96^{\circ} \mathrm{E}, 43.68^{\circ} \mathrm{N}\right)$ of the SIM data base. The $\mathrm{SWI}_{m}$ derived from $w_{g}$ and the corresponding root-zone soil moisture content are shown. This cell was chosen among the 9258 grid cells for which the exponential filter performs well $(N=0.86)$ 


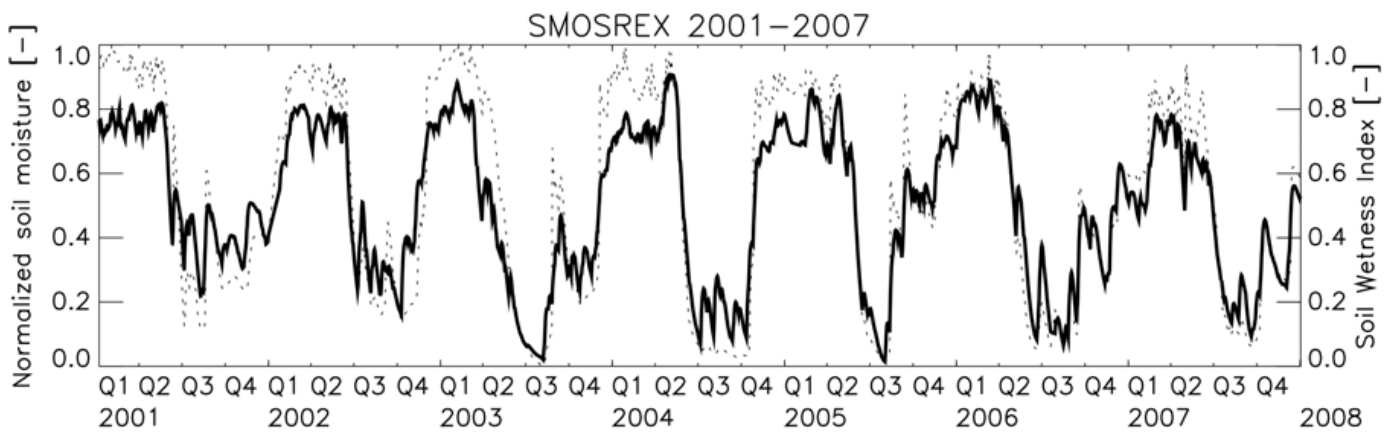

Fig. 6. Soil water index $\left(\mathrm{SWI}_{m}[-]\right)$ at $30 \mathrm{~cm}$ derived from $w_{g}[-]$ (scaled surface soil moisture observations at 0-6 $\mathrm{cm}$, solid line) and $w_{2}[-]$ (scaled soil moisture observations at $30 \mathrm{~cm}$, dashed line), for the SMOSREX station over a 7 year period (from January 2001 to December 2007). The characteristic time length of the exponential filter $T=6$ days is used, i.e. the best-fit value for the 7 year period.

Table 3. The retrieved optimum characteristic time length $T_{\mathrm{opt}}$ of the recursive formulation of an exponential filter for each year (2001 to 2007) of the SMOSREX data set, and for the pooled (2001-2007) data set, at $w_{2}$ (a depth of $30 \mathrm{~cm}$ ). Statistical scores are given for each period: the correlation coefficient $r$, the root mean square error (RMSE), the bias, the Nash-Sutcliffe coefficient $(N)$ corresponding to $T_{\mathrm{opt}}$, and to the $T_{\mathrm{opt}}$ of the pooled data set (6 days).

\begin{tabular}{lrrrrrl}
\hline Period & $\begin{array}{r}T_{\text {opt }} \\
\text { (days) }\end{array}$ & $r$ & RMSE & bias & $N$ & $\begin{array}{l}N \text { for } \\
T=6 \text { days }\end{array}$ \\
\hline 2001 & 11 & 0.792 & 0.101 & 0.0001 & 0.557 & 0.512 \\
2002 & 11 & 0.966 & 0.141 & -0.004 & 0.863 & 0.847 \\
2003 & 9 & 0.953 & 0.140 & 0.066 & 0.839 & 0.834 \\
2004 & 5 & 0.976 & 0.140 & 0.030 & 0.880 & 0.878 \\
2005 & 3 & 0.969 & 0.097 & 0.035 & 0.904 & 0.893 \\
2006 & 6 & 0.978 & 0.086 & -0.035 & 0.927 & 0.927 \\
2007 & 6 & 0.979 & 0.077 & 0.001 & 0.935 & 0.935 \\
$2001-2007$ & 6 & 0.956 & 0.121 & 0.026 & 0.858 & 0.858 \\
\hline
\end{tabular}

and because it is a representative grid cell compared to the average properties of each individual grid cell. For this grid cell $T_{\text {opt }}=10$ days, which is less than the average value (14.2), the thickness of the root-zone is $1.4 \mathrm{~m}$ and the fractions of clay and sand are 0.32 and 0.38 , respectively.

Across the full data set, the performance of the filter is $\operatorname{good}(N$ is higher than 0.7 for about $50 \%$ of the grid cells), and the variability of $T_{\mathrm{opt}}$ throughout the SIM domain is rather small with $50 \%$ of the values ranging mostly from 10 to 15 days. The highest values of $T_{\text {opt }}$ are found in the mountainous areas of the Alps and Pyrenees, and this may be explained by contrasting climatic conditions (snow cover, freezing, thawing etc.) compared to the plain areas (Fig. 7).

\subsection{Impact of soil depth/thickness}

Equation (1) shows that $T_{\mathrm{opt}}$ does depend on the soil depth or thickness for which $\mathrm{SWI}_{m}$ is computed. Soil moisture observations at SMOSREX are available at depths between 10 and $90 \mathrm{~cm}$, and the $\mathrm{SIM}$ derived $\mathrm{SWI}_{m}$ may correspond to
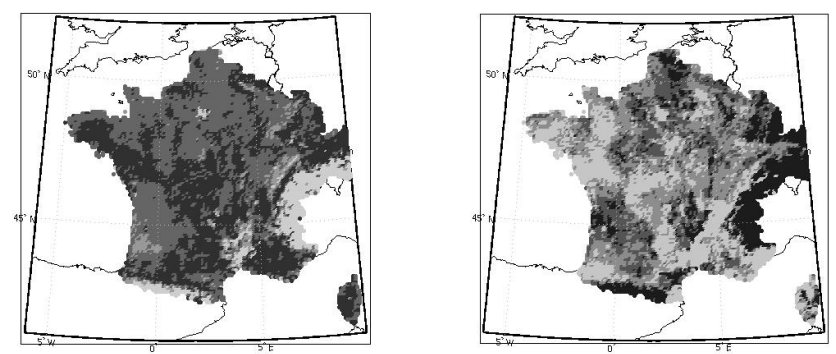

Fig. 7. Results of the recursive formulation of the exponential filter over France based on modelled soil moisture (SIM) for a 2-year period: Nash-Sutcliffe coefficient $N$ of the $\mathrm{SWI}_{m}[-]$ derived from $w_{g}[-]$ (scaled surface soil moisture simulations left), optimised characteristic time length $T_{\mathrm{opt}}$ of the recursive formulation of the exponential filter (right). The results are given for variable values of the soil thickness (from 0.2 to $2.0 \mathrm{~m}$ ). Dark to light-grey classes correspond to values of $N$ and $T_{\text {opt }}$ binned in 4 intervals of decreasing value: $[\operatorname{good}(N>0.7)$, fair $(0.5>N>0.7)$, poor $(0.2>N>0.5)$, inadequate $(N<0.2)]$ and $[>15 \mathrm{~d}, 12-15 \mathrm{~d}, 10-12 \mathrm{~d},<10 \mathrm{~d}]$, respectively.

contrasting soil thickness values. Therefore, it is possible to compare the $\mathrm{SWI}_{m}$ derived from the surface soil moisture observations at several depths or for several soil thickness values and to obtain the corresponding $T_{\mathrm{opt}}$ values.

Figure 9(left) presents the retrieved $T_{\text {opt }}$ for the individual sensors installed at different depths within the SMOSREX soil moisture profile (from $10 \mathrm{~cm}$ to $90 \mathrm{~cm}$ ). As expected, it is found that $T_{\mathrm{opt}}$ increases with the considered soil depth. In Fig. 9(right) the $T_{\text {opt }}$ values are presented as a function of the soil thickness, for SMOSREX (integrated from the surface to $10 \mathrm{~cm}$ and up to $90 \mathrm{~cm}$ deep), and for SIM. In the case of SIM, binned and averaged values of $T_{\mathrm{opt}}$ are presented, for different soil thickness values (19 classes of soil thickness are used, from $22 \mathrm{~cm}$ to $197 \mathrm{~cm}$ ). The $T_{\text {opt }}$ derived from the simulated profiles are consistent with the observed ones. 


\subsection{Impact of soil characteristics}

Other parameters with a potential impact on $T_{\text {opt }}$ are soil texture (clay and sand fraction), the bulk density, and the organic matter content, as they influence the infiltration capacity of the soil. Observed soil characteristics are available for SMOSMANIA (Table 1). For SIM, the model simulations account for soil texture, only.

In the case of SMOSMANIA, despite the results discussed in Sect. 4.1.1 where it was shown that sandy soils tended to have the lowest $N$ values, a detailed analysis of correlation of particle size distribution with $N$ did not present any conclusive results.

In the case of SIM, over France, soil texture has little influence on $T_{\mathrm{opt}}$, as shown by Fig. 10. In Fig. 10, the retrieved $T_{\text {opt }}$ is displayed as a function of clay and sand fractions, for the dominant soil thickness class $(1.50 \pm 0.05 \mathrm{~m})$. In order to reduce the influence of climatic conditions on the retrieval of $T_{\text {opt }}$, attempts were made to analyse the correlation over regions of $80 \times 80 \mathrm{~km}$. The results obtained (not shown) were similar to those presented in Fig. 10. Consequently, it is concluded that soil texture may not play a significant role in the determination of $T_{\mathrm{opt}}$.

\subsection{Impact of climate}

As mentioned earlier, $T_{\mathrm{opt}}$ may be affected by local climate conditions. This assumption is further supported by the results in Table 3, where a rather large inter-annual variability of $T_{\mathrm{opt}}$ is observed for SMOSREX. In order to explore this climate impact on $T_{\mathrm{opt}}$, the SIM data base was used. All the $T_{\text {opt }}$ values of the main depth class $(1.50 \pm 0.05 \mathrm{~m})$ were extracted over a south-north transect extending from the Mediterranean part of the Rhône valley to the Saône plain $\left(44.8^{\circ} \mathrm{N}-46.9^{\circ} \mathrm{N}, 4.6^{\circ} \mathrm{E}-5.4^{\circ} \mathrm{E}\right)$. This transect presents a strong climatic gradient, with higher temperatures in the southern part (subject to a Mediterranean climate) than in the northern part (subject to a more temperate, continental climate), and a different precipitation regime. The average wind speed is also stronger in the southern part (Troen and Patersen, 1989). The extracted $T_{\text {opt }}$ values were binned and averaged over regular intervals of $50 \mathrm{~km}$. Figure 11 shows that $T_{\mathrm{opt}}$ tends to increase from the Mediterranean region to the Saône plain. Lower values of $T_{\mathrm{opt}}$ are representative of a faster response of $\mathrm{SWI}_{m}$ to $w_{g}$ and this is consistent with the higher evaporation demand (higher temperatures and wind speed) and the less frequent, but more intense, precipitation events observed in the southern part of the transect.

\section{Discussion}

This study provides several insights into the use of the semiempirical approach developed by Wagner et al. (1999) to retrieve the root-zone soil moisture from remote sensing surface soil moisture estimates. It is shown that the main factor impacting on the retrieval is soil depth or soil thickness ( $T_{\mathrm{opt}}$ increases with soil depth or soil thickness). The $T_{\text {opt }}$ values vs. soil thickness as derived from the simulated profiles or from the observed ones at SMOSREX are consistent. This study does not permit to establish a link between $T_{\text {opt }}$ and soil texture (fraction of clay or sand).

The dominant climatic conditions within a region may influence $T_{\text {opt }}$. The data on Fig. 11, are obtained from model simulations throughout the Rhône valley, which suggests that a climate factor may exist. However, it is difficult to find a climate effect on $T_{\text {opt }}$ derived from the full SIM data set. The Rhône valley example is a rather extreme case. The Rhône gradient found on $T_{\mathrm{opt}}$ from model simulations only suggests that a climate factor may exist. Further investigation is needed to consolidate this result.

The exponential filter was shown to significantly lack sensitivity to $T_{\text {opt }}$. The results presented in Tables 2 and 3 have different Nash-Sutcliffe coefficients corresponding to different $T$ values ( $T_{\mathrm{opt}}$ and averaged $T_{\mathrm{opt}}$ ). Particularly the results of Table 3 show this lack of sensitivity. While an interannual variability of $T_{\mathrm{opt}}$ exists, the difference between the two values of $N$ calculated for each year with $T_{\text {opt }}$ or $T=6$ days at SMOSREX is low. The actual difference between the values of $N$ is less than $2 \%$ and therefore $N$ remains at a high level. Similarly, using the averaged $T_{\mathrm{opt}}$ for the twelve stations of the SMOSMANIA network instead of their station-specific $T_{\text {opt }}$ values causes a difference of less than $4 \%$. The high accuracy of the result using either $T_{\mathrm{opt}}$ or a globally averaged $T$ and the apparent insensibility of the retrieval method to changes in $T_{\mathrm{opt}}$ are interpreted as an advantage of this method, as a range of $T$ values may be applied to obtain good estimates of $\mathrm{SWI}_{m}$. However these results may also lead to the interpretation that this insensitivity shows that the method is not fully adequate.

In order to assess the added value of the filter, the scores were calculated for $T=0$ day, which is the equivalent of a direct replacement of the modelled root-zone soil moisture data with the surface soil moisture observations, without filtering. At the SMOSMANIA stations and at SMOSREX, the comparison of the two time series shows high correlations $\left(r^{2}>0.5\right)$, except for three stations (LHS, MTM, LZC). It is interesting to note that for these stations, the filter score $N$ (Table 2) is rather low, also. This is not a general rule: although $N$ is low for SBR, the $5 \mathrm{~cm}$ vs. $30 \mathrm{~cm}$ correlation is high $\left(r^{2}=0.66\right)$.

Regarding the correlation between the surface soil moisture and deeper layers simulated by ISBA, a number of factors (soil texture, vegetation coverage, time) were investigated by Calvet and Noilhan (2000). A decoupling between the two layers may occur for low vegetation coverage (favouring direct soil evaporation). The decoupling is more pronounced before dusk, and for sandy soils. Figure 12 shows the distribution of SIM $N$ values for $T=T_{\mathrm{opt}}$, $T=0$ day, and $T=15$ days (i.e. the median $T_{\mathrm{opt}}$ value) over France. Very similar distributions are obtained for $T=15$ days 


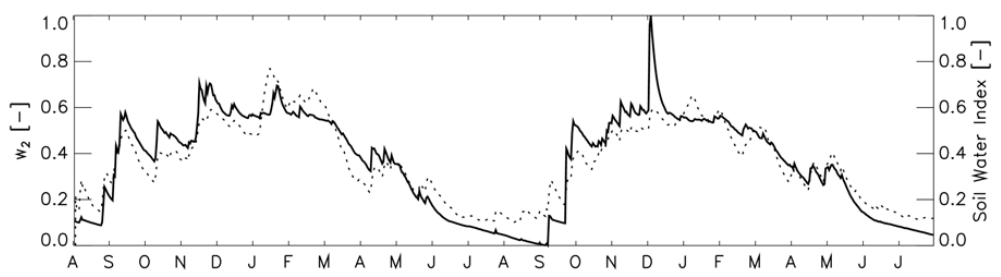

Fig. 8. Results of the recursive formulation of the exponential filter over a SIM grid cell (chosen among the 9258 pixels of the SIM database) for a 2-year period (2003-2004): $\mathrm{SWI}_{m}[-]$ derived from $w_{g}[-]$ (scaled surface soil moisture simulations, dashed line) and the reference root-zone soil water content, $w_{2}[-]$, simulated by SIM (scaled root zone soil moisture simulations, solid line).
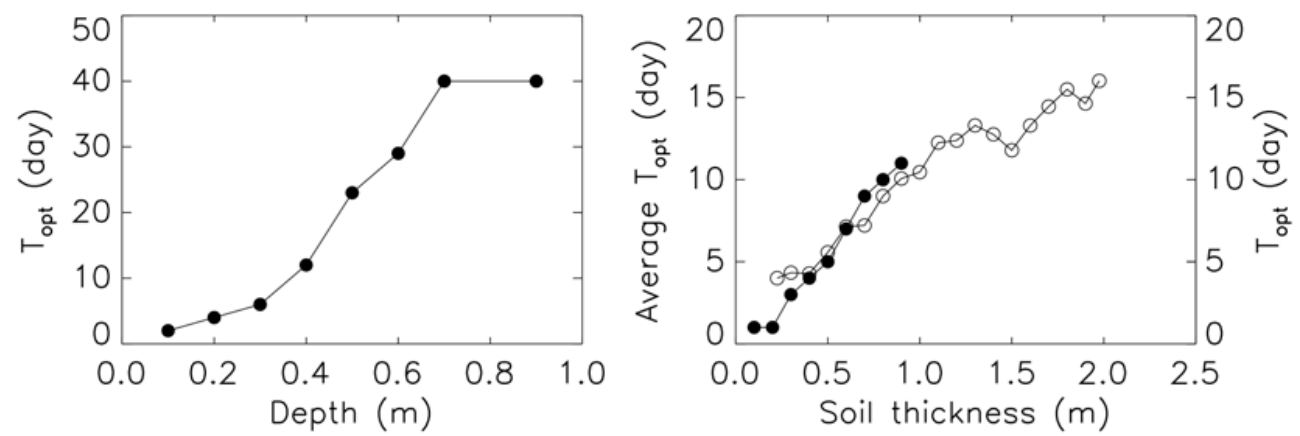

Fig. 9. Optimised characteristic time length of the recursive formulation of the exponential filter $\left(T_{\mathrm{opt}}\right)$ for reference scaled root-zone soil moisture (left) observations at individual depths of the SMOSREX soil moisture profile (from 10 to $90 \mathrm{~cm}$ ), (right) integrated profile observations of SMOSREX (full circles) and simulations of SIM (open circles) for various soil thicknesses. In the case of SIM, average $T_{\mathrm{opt}}$ values are plotted.

and for $T=T_{\mathrm{opt}}$. Indeed, the soil thickness (the main driver of $T_{\mathrm{opt}}$, as discussed in Sect. 4.2) used in SIM is predominantly (65\%) distributed between $1.35 \mathrm{~m}$ and $1.65 \mathrm{~m}$. The comparison of the simulated surface vs. deep scaled soil moisture (i.e. $T=0$ day) shows that surface values may be fair estimates of root-zone values: $N>0.5$ for $32 \%$ of the grid cells. On the other hand, good estimates $(N>0.7)$ are never achieved with this method. For $T=15$ days, the proportions of fair and good estimates reach $49 \%$ and 37\%, respectively. An attempt (not shown) was made to assess the SIM $N$ values for $T=6$ days, i.e. for the median $T_{\text {opt }}$ for SMOSMANIA and SMOSREX. The proportions of fair and good estimates reach 56\% and $29 \%$, respectively. This shows that while the proportion of good estimates is sensitive to $T$, the proportion of acceptable estimates (either fair or good) does not vary much with $T$ ( $86 \%$ and $85 \%$ for $T=15$ days and $T=6$ days, respectively).

\section{Conclusions}

In this paper, the use of an exponential filter to retrieve the scaled root-zone soil moisture $\left(\mathrm{SWI}_{m}\right)$ from surface soil moisture observations or simulations, was assessed using modelled and real data over France. The recursive formulation of the exponential filter was implemented as it reduced computational time and eliminated the need to store and reprocess long data records (all data in the interval $\left[t_{n}-3 T\right.$, $\left.t_{n}\right]$ ) each time a new observation was available. Generally, the use of this method was satisfactory, after the characteristic time length of the filter $(T)$ was optimised $\left(T_{\text {opt }}\right)$. The main features of the seasonal and interannual variability of $\mathrm{SWI}_{m}$ were captured by the filtering method.

Combining the rich SMOSMANIA and SMOSREX in situ data sets with synthetic data from land surface simulations over France, the impact of different factors on the single parameter of this approach $\left(T_{\mathrm{opt}}\right)$ could be assessed:

- $T_{\text {opt }}$ was found to vary with the soil depth (soil thickness) at (over) which $\mathrm{SWI}_{m}$ was considered.

- No clear link between $T_{\mathrm{opt}}$ and soil and climate properties was found.

- The exponential filter was not very sensitive to interannual or spatial variations of $T_{\mathrm{opt}}$, and the application of a constant average value of $T$ did not significantly affect the quality of the retrievals.

- Over France, the proportion of acceptable estimates (either fair or good) did not vary much with $T$. However, the area extent of good estimates varied with $T$.

This study underlines the potential of the exponential filter and its recursive formulation for root zone soil moisture retrieval. No land surface model or meteorological observations (like precipitation) are needed to retrieve $\mathrm{SWI}_{m}$ and 

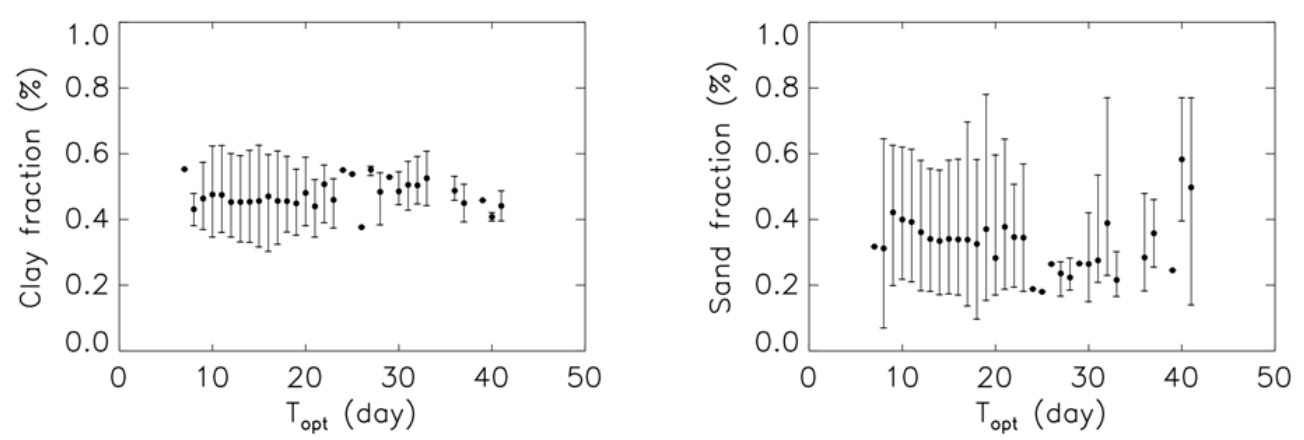

Fig. 10. Results of the recursive formulation of the exponential filter over the SIM domain for a 2-year period: mean clay and sand fraction versus the optimised characteristic time length of the exponential filter $\left(T_{\mathrm{opt}}\right)$ for the most frequent thickness of the root-zone soil layer of $\operatorname{SIM}(1.50 \mathrm{~m} \pm 0.05 \mathrm{~m})$. The error bars correspond to the standard deviation.

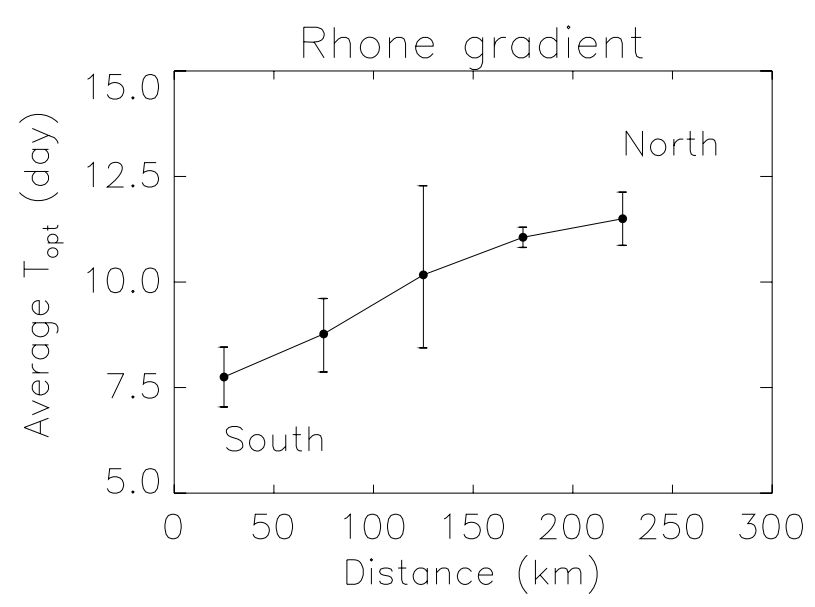

Fig. 11. Results of the recursive formulation of the exponential filter over the SIM domain for a 2-year period: average optimised characteristic time length of the exponential filter $\left(T_{\text {opt }}\right)$ along a SouthNorth transect from the Rhône valley to the Saône plain. Binned values are presented each $50 \mathrm{~km}$ for the most frequent thickness of the root-zone soil layer of SIM $(1.50 \mathrm{~m} \pm 0.05 \mathrm{~m})$ and the most frequent fraction of clay (12 to $21 \%$ ). The vertical bars indicate the standard deviation of the binned $T_{\mathrm{opt}}$.

the discussed method relies solely on surface soil moisture estimates. As surface soil moisture can be observed from space by remote sensing techniques, the performance of the exponential filter is particularly interesting in areas with atmospheric information of poor quality.

Acknowledgements. The development of the SMOSMANIA network was co-funded by Météo-France, CNES, and ESA. The work of C. Albergel and C. Rüdiger at CNRM was supported by CNES. The authors want to acknowledge the contribution of a number of Météo-France colleagues to SMOSMANIA: P. Grégoire, M. Leroy, J. L. Ajas, F. Baillet, Y. Balaguer, D. Bettinelli, J. Y. Caillaud, P. Caseau, C. Genevier, P. Gérard, G. Hertz, C. Izard, P. Léon, J. C. Maillard, D. Malet, J. L. Marino, G. Moreau, J. Poitevin, P. Salvetat, P. Taurel, and R. Voirin. The authors thank A. Chanzy (INRA) for fruitful discussion. The SMOSREX project was co-

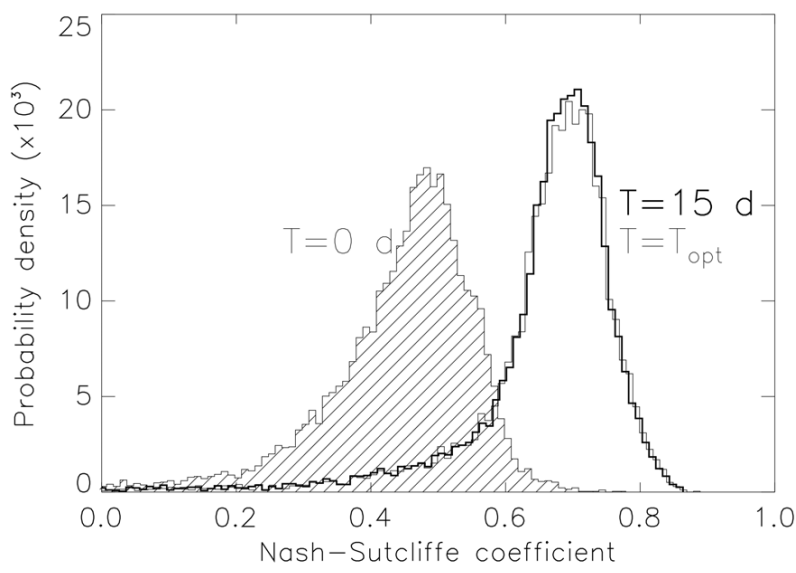

Fig. 12. Performance of the recursive formulation of the exponential filter over France based on modelled soil moisture (SIM) for a 2year period: statistical distribution of the Nash-Sutcliffe coefficient $N$ of the $\mathrm{SWI}_{m}$ derived from $w_{g}$ (scaled surface soil moisture simulations), for different values of the characteristic time length $(T)$ of the filter, optimised value $T_{\text {opt }}$, single median value of 15 days, and $T=0$ day. Note that positive values of $N$ are presented, only.

founded by the "Programme National de Télédétection Spatiale" and by the "Programme Terre, Océan, Surfaces Continentales et Atmosphère (CNES)", and by participants to the experiment: CESBIO (CNES, CNRS, IRD, UPS), CNRM/GAME (Météo-France, CNRS), INRA, and ONERA.

Edited by: N. Verhoest

\section{References}

Boone, A., Calvet, J.-C., and Noilhan, J.: Inclusion of a third soil layer in a land surface scheme using the force-restore method, J. Appl. Meteorol., 38, 1611-1630, 1999.

Calvet, J.-C. and Noilhan, J.: From near-surface to root-zone soil moisture using year-round data, J. Hydrometeorol., 1, 393-411, 2000. 
Calvet, J.-C., Fritz, N., Froissard, F., Suquia, D., Petitpa, A., and Piguet, B.: In situ soil moisture observations for the CAL/VAL of SMOS: the SMOSMANIA network, International Geoscience and Remote Sensing Symposium, IGARSS, Barcelona, Spain, 23-28 July 2007, 1196-1199, doi:10.1109/IGARSS.2007.4423019, 2007.

Ceballos, A., Scipal, K., Wagner, W., and Martinez-Fernandez, J.: Validation of ERS scatterometer derived soil moisture data in the central part of the Duero Basin, Spain, Hydrol. Process., 25(19), 1549-1566, 2005.

De Rosnay, P., Calvet, J.-C., Kerr, Y., Wigneron, J.-P., Lemaître, F., Escorihuela, M.J., Muñoz Sabater, J., Saleh, K., Barrie, J., Coret, L., Cherel, G., Dedieu G., Durbe, R.., Fritz, N., Froissard, F., Kruszewski, A., Lavenu, F., Suquia, D., and Waldteufel, P.: SMOSREX: A long term field campaign experiment for soil moisture and land surface processes remote sensing, Remote Sens. Environ., 102, 377-389, 2006.

Durand, Y., Brun, E., Merindol, L., Guyomarc'h, G., Lesaffre, B., and Martin, E.: A meteorological estimation of relevant parameters for snow models, Ann. Glaciol., 18, 65-71, 1993.

Entekhabi, D., Nakamura, H., and Njoku, E. G.: Solving the Inverse problem for soil moisture and temperature profiles by sequential assimilation of multifrequency remotely sensed observations, IEEE T. Geosci. Remote, 32, 438-448, 1994.

Escorihuela, M. J, de Rosnay, P., Kerr, Y., and Calvet, J.-C.: Influence of bound water relaxation frequency on soil moisture measurements, IEEE T. Geosci. Remote, 45(12), 4067-4076, doi:10.1109/TGRS.2007.906090, 2007.

Habets, F., Ducrocq, V., and Noilhan, J.: Prévisions hydrologiques et échelles spatiales: l'exemple des modèles opérationnels de Météo-France, C. R. Geosci., 337, 181-192, 2005.

Habets, F., Boone, A., Champeaux, J.-L., Etchevers, P., Franchisteguy, L., Leblois, E., Ledoux, E., Le Moigne, P., Martin, E., Morel, S., Noilhan, J., Quintana-Seguí, P., Rousset-Regimbeau, F., and Viennot, P.: The SAFRAN-ISBA-MODCOU hydrometeorological model applied over France, J. Geophys. Res., 113, D06113, doi:10.1029/2007JD008548, 2008.

Houser, P. R., Shuttleworth, W. J., Famiglietti, J. S., Gupta, H. V., Syed, K. H., and Goodrich, D. C.: Integration of Soil Moisture Remote Sensing and Hydrologic Modelling Using Data Assimilation, Water Resour. Res., 34(12), 3405-3420, 1998.

Jackson, T. J.: Profile soil moisture from space measurements, J. Irrig. Drain. E.-ASCE, 106, 81-92, 1980.

Jackson, T. J.: Soil water modelling and remote sensing, IEEE T. Geosci. Remote, GE-24, 37-46, 1986.

Kerr, Y., Waldteufel, P., Wigneron, J.-P., Martinuzzi, J.-M., Font, J., and Berger, M.: Soil Moisture retrieval from space: the Soil Moisture and Ocean Salinity (SMOS) mission, IEEE T. Geosci. Remote, 39, 1729-1736, 2001.

Kerr, Y.: Soil moisture from space: Where are we? Hydrogeol. J., 15, 117-120, 2007.

Masson, V., Champeaux, J.-L., Chauvin, F., Meriguet, C., and Lacaze, R.: A global database of land surface parameters at $1 \mathrm{~km}$ resolution in meteorological and climate models, J. Climate, 9, 1261-1282, 2003.

Nash, J. and Sutcliffe, J.: River flow forecasting through conceptual models, part Ii - a discussion and principles, J. Hydrol., 10, 282290, 1970.

Noilhan, J. and Planton, S.: A simple parameterisation of Land Sur- face Processes for meteorological model, Mon. Weather Rev., 117, 356-549, 1989.

Noilhan, J. and Mahfouf, J.-F.: The ISBA land surface parameterisation scheme, Global Planet. Change, 13, 145-149, 1996.

Pellarin, T., Calvet, J.-C., and Wagner, W.: Evaluation of ERS scatterometer soil moisture products over a half-degree region in southwestern France, Geophys. Res. Lett., 33, L17401, doi:10.1029/2006GL027231, 2006.

Quintana-Segui, P., Lemoigne, P., Durand, Y., Martin, E., Habets, F., Baillon, M., Canellas, C., Franchisteguy, L., and Morel, S.: Analysis of near surface atmospheric variables: Validation of the SAFRAN analysis over France, J. Appl. Meteorol. Clim., 47, 92107, 2008.

Ragab, R.: Towards a continuous operational system to estimate the root-zone soil moisture from intermittent remotely sensed surface soil moisture, J. Hydrol., 173, 1-4, 1-25, 1995.

Robinson, D. A., Campbell, C. S., Hopmans, J. W., Hornbuckle, B. K., Jones, S. B., Knight, R., Ogden, F., Selker, J., and Wendroth, O.: Soil moisture measurement for ecological and hydrological watershed-scale observatories: a review, Vadose Zone J., 7, 358-389, doi:10.2136/vzj2007.0143, 2008.

Rüdiger, C., Calvet, J.-C., Gruhier, C., Holmes, T., De Jeu, R., and Wagner, W.: An intercomparison of ERS-Scat and AMSR-E soil moisture observations with model simulations over France, J. Hydrometeorol., in press, 2008.

Sabater, J. M., Jarlan, L., Calvet, J.-C., Bouyssel, F., and De Rosnay, P.: From near surface to root zone soil moisture using different assimilation techniques, J. Hydrometeorol., 8, 94-206, 2007.

Schmugge, T. J.: Remote Sensing of Soil Moisture: Recent Advances, IEEE T. Geosci. Remote, GE21, 145-146, 1983.

Stroud, P. D.: A recursive exponential filter for time-sensitive data, Los Alamos national Laboratory, LAUR-99-5573, available at: public.lanl.gov/stroud/ExpFilter/ExpFilter995573.pdf, (last access July 2008) 1999.

Troen, I. and Petersen, E. L.: European Wind Atlas, ISBN 87-5501482-8, Risbø National Laboratory, Roskilde, 656 pp., 1989.

Wagner, W.: Soil moisture retrieval from ERS scatterometer data, Ph.D. thesis, University of Technology, Vienna, 101 pp., 1998.

Wagner, W., Lemoine, G., and Rott, H.: A method for estimating soil moisture from ERS scatterometer and soil data, Remote Sens. Environ., 70, 191-207, 1999.

Wagner, W., Scipal, K., Pathe, C., Gerten, D., Lutch W., and Rudolph, B.: Evaluation of the agreement between the first global remotely sensed soil moisture data with model and precipitation data, J. Geophys. Res.-Atmos., 108(19), 4611, doi:10.1029/2003JD003663, 2003.

Walker, J. P., Willgoose, G. R., and Kalma, J. D.: One-dimensional soil moisture profile retrieval by assimilation of near-surface measurements: A simplified soil moisture model and field application, J. Hydrometeorol., 2, 356-373, 2001a.

Walker, J. P., Willgoose, G. R., and Kalma, J. D.: One-dimensional soil moisture profile retrieval by assimilation of near-surface observations: a comparison of retrieval algorithms, Adv. Water Resour., 24(6), 631-650, 2001 b.

White, I., Knight, J. H., Zegelin, S. J., and Topp, G. C.: Comments on "Considerations on the use of time-domain reflectometry (TDR) for measuring soil water content", edited by: Whalley, W. R., Response, Eur. J. Soil. Sci., 45, 503-510, 1994. 